\title{
Globalization, International Factor Mobility, and Wage Inequality
}

Shigemi Yabuuchi

Aichi University, Nagoya, Japan

\begin{abstract}
The international movement of economic factors such as capital and skilled labor has complex effects on the economies involved, especially when multiple factors move at the same time. One important effect is the potential change in wage inequality between skilled and unskilled labor-particularly, in developing countries that have agreed to trade with developed countries. This study considers a small open economy with two goods and three factors to determine whether wage inequality increases or decreases due to increased movement of these factors. The key findings are that wage inequality can unambiguously increase and decrease, under certain circumstances regarding the capital intensity of the sector(s), the initial amount of foreign factors, and the shares of factors in national income.
\end{abstract}

JEL Classifications: F15, F16, F22, R23

Keywords: International Factor Mobility, Wage Inequality, Unemployment

\footnotetext{
* Corresponding Author: Shigemi Yabuuchi; Department of Economics, Aichi University, Hiraike, Nakamura-ku, Nagoya, Aichi 467-8501, Japan; Tel: +81 561745760, Fax:+81 561745760, E-mail: yabuuchi@aichi-u.ac.jp. 


\section{Introduction}

International trade and investment lead to the international movement of factors; that is, labor and capital cross borders to participate in a foreign economy. Economic relationships between countries are complex in nature and particularly affect the economies and population of newly trading (and often developing) countries. Although the topic has attracted significant research attention, prior studies on the effects of factor movement have limited focus.

The effects of international trade and investment on the wage inequality between skilled and unskilled labor have been investigated extensively as in Davis (1998), Feenstra and Hanson (1996, 1997), Jones and Marjit (2003), Marjit and Acharyya (2003), and Marjit and Kar (2005). Among others, Marjit and Kar (2005) examine the implications of labor emigration on the wage gap between skilled and unskilled labor in a developing economy. They find that emigration of unskilled labor may increase the gap between skilled and unskilled wage rates, while emigration of skilled labor can reduce it. Their analysis has been extended to include the Harris-Todaro labor allocation mechanism in papers such as Beladi et al. (2008), Yabuuchi (2009), Lee et al. (2010), and Banerjee and Nag (2011).

However, these studies on the effects of international factor movement on wage inequality have examined only one factor at a time. This approach ignores the fact that the movement of factors, which is particularly seen following the establishment of a Free Trade Agreement (FTA) or an Economic Partnership Agreement (EPA), may often be simultaneous. For example, capital and skilled labor are introduced to the host country as a form of Foreign Direct Investment (FDI). Also, unskilled labor emigrates from a developing economy to find employment as guest workers in a developed country, while at the same time skilled labor immigrates to the developing country as a part of EPA.

FTA and EPA have been concluded extensively all over the world. This is partly because of the failure of establishing new multilateral rules under the World Trade Organization (WTO) framework. FTAs and Customs Unions (CUs) originally have been established in order to liberalize trade between the member countries. The traditional theory of customs union covers this field of study. However, recent trend on the agreements such as Trans-Pacific Strategic Economic Partnership Agreement (TPP), Regional Comprehensive Economic Partnership (RCEP), and various EPAs include liberalization and/or free movement of factors within the regions. They may bring with 
them simultaneous movement of factors, such as capital and skilled labor. For example, the US may bring with TPP medical institutions into Japan, causing the inflow of both medical capital and medical experts into the market. Also, Japan accepts Filipino nurses and care workers following the establishment of the Japan-Philippine EPA agreement in 2008, while Filipino workers (mostly unskilled) in Japan increased from about 40,000 in 2009 to 80,000 in 2013. RCEP is also expected to accelerate investment in the region. This study will present a simple model that captures the characteristic features of the international movement of multiple factors.

Furthermore, it is a characteristic feature of developing economies that they have a dual structure between the rural and urban areas; that is, the economic activities of these two regions are not well-integrated. Rural areas often have highly different levels of resources, capital, and human capital, as well as distinctive demands compared to urban areas. The existence of the dual structure between these two areas can make the examination of the effects of international factor movement on wage inequality slightly more difficult to interpret. Thus, the purpose of this paper is to examine the effects of simultaneous international movement of factors on wage inequality in a developing economy with dual structure. To this end, this study uses the model developed in Yabuuchi (2009) that extends the Marjit-Kar model by including two new factors that characterize the dual economy: unskilled labor that can move between sectors and urban unemployment. We find that the simultaneous movement of different factors can sometimes have an unambiguous effect on wage inequality and, furthermore, it can decrease the inequality when certain conditions regarding the capital intensity of the sector(s), the initial amount of foreign factors, and the shares of factors in national income are met.

The structure of the paper is as follows. The model and basic assumptions are presented in Section II. Section III examines the impacts of simultaneous movement of factors on wage inequality. Finally, Section IV concludes the paper.

\section{The Model}

Following Yabuuchi (2009), let us consider a small open economy in which there are two goods and three factors. Sector 1 employs unskilled labor, $L_{1}$, and capital, $X_{1}$, 
to produce agricultural good $X_{1}$, while Sector 2 uses unskilled labor, $L_{2}$, capital, $K_{2}$, and skilled labor, $\mathrm{H}_{2}$, to produce manufacturing good $X_{2}$. Unskilled labor and capital are used in both sectors, while skilled labor is fully used only in Sector 2. Capital is mobile between the sectors. Unskilled labor is mobile, but its allocation between sectors is determined by the mechanism of Harris and Todaro (1970). The wage rate of the unskilled labor in the rural sector $w_{1}$ is competitive and flexible. Thus, unskilled labor is fully employed in the rural sector. However, the unskilled wage rate in the urban sector is fixed and higher than the rural wage rate because of various political and institutional reasons, such as trade unions, minimum wage laws, and industrial promotion policies. Thus, rural workers want to move to the urban area, but some of the migrant workers cannot gain employment, thus creating an unemployment group. Let $L_{u}$ denote urban unemployment. In equilibrium, the rural wage rate will be equal to the expected urban wage rate; that is, the fixed urban wage rate $w_{2}$ times the probability of getting a job in the urban area $\left(L_{2} /\left(L_{2}+L_{u}\right)\right)$. Thus, the labor allocation mechanism between the sectors is shown as follows:

$$
w_{1}(1+\lambda)=w_{2}
$$

where $\lambda=L_{u} / L_{2}$.

Upon assumption that markets are perfectly competitive, the zero profit conditions can be expressed as:

$$
\begin{gathered}
p_{1}=a_{L 1} w_{1}+a_{K 1} r \\
p_{2}=a_{L 2} w_{2}+a_{K 2} r+a_{H 2} S
\end{gathered}
$$

where $a_{i j}$ is the amount of the $i^{\text {th }}$ factor used in the $j^{\text {th }}$ industry to produce one unit of the output, whereas $s$ is the wage rate of skilled labor, $r$ is rent of capital, and $p_{j}$ is the price of the $j^{\text {th }} \operatorname{good}(j=1,2)$. This paper assumes that all goods are tradable and that their prices are exogenously given based on the small-country assumption. In order to simplify the analysis, it is assumed that Sector 2 employs skilled labor in fixed proportion; i.e., $a_{H 2}$ is constant.

Under the present setup, the employment condition in each factor market can be expressed as 


$$
\begin{gathered}
a_{L 1} X_{1}+a_{L 2} X_{2}+\lambda a_{L 2} X_{2}=L+L^{*} \\
a_{K 1} X_{1}+a_{K 2} X_{2}=K+K^{*}
\end{gathered}
$$

and

$$
a_{K 1} X_{1}+a_{K 2} X_{2}=K+K^{*}
$$

where $L, H$, and $K$ are the domestic endowments of unskilled labor, skilled labor, and capital, respectively, while $L^{*}, H^{*}$, and $K^{*}$ are the foreign inflows of unskilled labor, skilled labor, and capital, respectively.

Thus, our model framework has the six unknown variables $w_{1}, s, r, X_{1}, X_{2}$, and $\lambda$, which are solved by Equations (1) (6) for the given parameters $w_{2}, p_{1}, p_{2}, L, H, K, L^{*}$, $H^{*}$, and $K^{*}$.

\section{International Factor Movement and Wage Inequality}

Let us now analyze the consequences of the international mobility of the different factors of production on the skilled-unskilled wage inequality. Note that there are three types of unskilled workers: rural, urban employed, and unemployed workers. Rural and urban employed workers earn a competitive rural wage rate $w_{1}$ and a fixed urban wage rate $w_{2}$, respectively. Thus, the average wage rate for unskilled labor is defined as:

$$
w_{A}=\lambda_{L 1} w_{1}+\lambda_{L 2} w_{2}
$$

Urban unemployed workers have no income. As shown by Beladi et al. (2008), therefore, it can be seen from Equation (7) that $w_{A}=w_{1}$ by using Equations (5) and (6). Thus, the change in the average wage rate for unskilled labor can be captured by that in the rural wage rate.

Solving Equation (18) presented in the Appendix for $\hat{w}$ and $\hat{s}$, the following system is obtained: 


$$
\begin{aligned}
& \hat{w}_{1}=\left(w_{1} \lambda \theta_{K 1} \theta_{H 2} / \Delta\right)\left\{\left(l * \lambda_{K 1} \hat{L}^{*}\right)+\left(h^{*} \Lambda_{L K} \hat{H}^{*}\right)-\left(k^{*} \lambda_{L 1} \hat{K}^{*}\right)\right\} \\
& \hat{s}=\left(w_{1} \lambda \theta_{L 1} \theta_{K 2} / \Delta\right)\left\{\left(l * \lambda_{K 1} \hat{L}^{*}\right)+\left(h^{*} \Lambda_{L K} \hat{H}^{*}\right)-\left(k^{*} \lambda_{L 1} \hat{K}^{*}\right)\right\}
\end{aligned}
$$

where $\Delta$ is the value of the determinant on the system's coefficient matrix; $l^{*} \equiv L^{*} /\left(L+L^{*}\right), h^{*} \equiv H^{*} /\left(H+H^{*}\right)$, and $k^{*} \equiv K^{*} /\left(K+K^{*}\right) ; \lambda_{i j}$ is the allocated share of factor $i$ in the $j^{\text {th }}$ sector (e.g., $\lambda_{K 1}=a_{K 1} X_{1} /\left(K+K^{*}\right)$ ); $\theta_{i j}$ is the distributive share of factor $i$ in the $j^{\text {th }}$ sector (e.g., $\theta_{H 2}=s a_{H 2} / p_{2}$ ); and $\Lambda_{L K}=\lambda_{K 2} \lambda_{L 1}-(1+\lambda) \lambda_{K 1} \lambda_{L 2}$. It can be seen that:

$$
\Delta=-\lambda w_{1} \lambda_{K 1} \theta_{H 2}\left[(1+\lambda) \lambda_{L 2}\left(\theta_{K 1}+\theta_{L 1} S_{L K}^{2}\right)+\lambda_{L 1}\left\{\left(\theta_{L 1} S_{L K}^{1}+\theta_{K 1} S_{K L}^{1}\right)-\theta_{K 1} S_{L L}^{1}\right\}\right]
$$

where $S_{L K}^{2}=\left(\partial a_{L 2} / \partial r\right)\left(r / a_{L 2}\right)$ and so on. Note that $\Delta<0$ since $S_{i k}^{j}>0(i \neq k)$ and $S_{i i}^{j}<0(i, k=\mathrm{L}, \mathrm{K} ; j=1,2)$.

In the Harris-Todaro model, it is conventionally assumed that Urban Sector 2 represents the manufacturing sector and that Rural Sector 1 represents the agricultural sector. Thus, it is natural to assume that Sector 2 is more capital intensive in terms of value. This assumption implies that $r a_{K 2} / w_{2} a_{L 2}>r a_{K 1} / w_{1} a_{L 1}$ and, therefore, $\Lambda_{L K}=\lambda_{K 2} \lambda_{L 1}-(1+\lambda) \lambda_{K 1} \lambda_{L 2}>0$.

Subtraction of Equation (8) from (9) yields

$$
\left(\hat{s}-\hat{w}_{1}\right)=\left(w_{1} \lambda \Theta / \Delta\right)\left\{\left(l * \lambda_{K 1} \hat{L}^{*}\right)+\left(h^{*} \Lambda_{L K} \hat{H}^{*}\right)-\left(k^{*} \lambda_{L 1} \hat{K}^{*}\right)\right\}
$$

where $\Theta=\left(\theta_{K 2} \theta_{L 1}-\theta_{K 1} \theta_{H 2}\right)$.

\section{A. Skilled and unskilled labor}

Particularly following the establishment of an EPA or FTA, the movement of skilled and unskilled labor from one country to another may occur simultaneously. Thus, it will be important and interesting to examine the effects of simultaneous movement of labor on the wage inequality in the developing country.

The movement may be in the same direction; that is, both skilled and unskilled labor emigrate from (or immigrate to) other member countries in search of better jobs and higher income. For example, immigration from Mexico to the United States and from southern European countries to Germany is commonly seen. However, the effect of this kind of labor movement on wage inequality is obvious from Equation (10). This is 
summarized in the following proposition.

Proposition 1. Simultaneous emigration (immigration) of skilled and unskilled labor will increase (decrease) the wage inequality if Sector 2 is capital intensive such that $\Theta=\left(\theta_{K 2} \theta_{L 1}-\theta_{K 1} \theta_{H 2}\right)>0$.

It can be seen from Equation (10) that international movements of skilled and unskilled labor have qualitatively the same effects on wage inequality if Sector 2 is more capital intensive in terms of value (i.e., $\left.\Lambda_{L K}=\lambda_{K 2} \lambda_{L 1}-(1+\lambda) \lambda_{K 1} \lambda_{L 2}>0\right)$. Thus, in the case where both labor types move in the same direction, the results depend on the factor intensity condition, which is derived in Yabuuchi (2009) for the case of the international movement of separate factors. This shows the robustness of the preceding results by Marjit and Kar (2005), Beladi et al. (2009), and Yabuuchi (2009), though the conditions differ according to the framework of the models. Marjit and Kar (2005) assume that unskilled labor is used only in sector $1\left(a_{L 2}=0\right.$ in the present model). Thus, the condition is simplified as $\theta_{K 2}>\theta_{K 1}$ since $\theta_{L 1}+\theta_{K 1}=1$ and $\theta_{H 2}+\theta_{K 2}=1$. On the other hand, Beladi et al. (2008) assume that all three factors are used in Sectors 1 and 2. The condition is then expressed as: $\theta_{K 2} \theta_{L 1}>\left(\theta_{K 1} \theta_{H 2}-\theta_{H 1} \theta_{K 2}\right)$.

The condition plays a crucial role in this paper as well. Thus, following Yabuuchi (2009), the implication of the condition is reviewed. For example, emigration of unskilled labor increases the wage rate $\left(w_{1}\right)$. This causes the induced change in the wage rate of skilled labor $(s)$. In order to examine the effect on $s$, Equations (3) and (4) are differentiated to obtain:

$$
\begin{aligned}
& \theta_{L 1} \hat{w}_{1}+\theta_{K 1} \hat{r}=0 \\
& \theta_{K 2} \hat{r}+\theta_{H 2} \hat{s}=0
\end{aligned}
$$

Equations (11) and (12) can be written as:

$$
\begin{aligned}
& \hat{r}=-\left(\theta_{L 1} / \theta_{K 1}\right) \hat{w}_{1} \\
& \hat{s}=-\left(\theta_{K 2} / \theta_{H 2}\right) \hat{r}
\end{aligned}
$$

lowers the rental of capital by $\left(\theta_{L 1} / \theta_{K 1}\right)$ percent, and an increase of one percent in the 
rent, in turn, decreases the skilled wage rate by $\left(\theta_{K 2} / \theta_{H 2}\right)$ percent to keep the prices of goods constant; thus, the following equation:

$$
\hat{s}=\left(\theta_{L 1} \theta_{K 2} / \theta_{H 2} \theta_{K 1}\right) \hat{w}_{1}=\left[\left(\theta_{K 2} / \theta_{H 2}\right) /\left(\theta_{K 1} / \theta_{L 1}\right)\right] \hat{w}_{1}
$$

Therefore, the skilled wage rate also increases due to the outflow of unskilled labor and subsequent increase in $w_{1}$. The effect on the wage inequality depends on the relative magnitude of the changes in the wage rates; that is, on the factor intensity condition. The increase in the skilled wage rate becomes larger if the capital intensity with respect to unskilled labor, $\left(\theta_{K_{2}} / \theta_{H_{2}}\right)$, in Sector 1 is small and the capital intensity with respect to skilled labor in Sector 2, $\left(\theta_{K 1} / \theta_{L 1}\right)$, is large. The effect of the inflow of skilled labor on the wage inequality is counter-intuitive, while the effect of the inflow of unskilled is intuitive. However, the factor intensity condition accommodates the intuition and the economic reasoning behind the changes in factor prices.

The more interesting case is when skilled and unskilled labor move in the opposite direction. If the FTA or EPA consists of both developed and developing countries, it is often observed that unskilled workers of developing countries immigrate to the developed countries as construction workers and salespersons. On the other hand, skilled workers of developed countries immigrate to the developing countries as computer engineers and accounting experts. Here, the effect of such labor movement on the wage inequality is examined. In order to capture the simultaneous movement of skilled and unskilled labor, it is assumed that:

$$
\hat{H}^{*}=-\alpha \hat{L}^{*}, \quad \hat{L}^{*}<0, \text { and } \hat{H}^{*}>0
$$

Substituting Equation (14) into (10), the following is obtained:

$$
\left(\hat{s}-\hat{w}_{1}\right)=\left(w_{1} \lambda \Theta / \Delta\right)\left(l * \lambda_{K 1}-\alpha h * \Lambda_{L K}\right) \hat{L} *
$$

Thus, it can be seen that $\left(\hat{s}-\hat{w}_{1}\right)>0$ if and only if $\Theta\left(l * \lambda_{K 1}-\alpha h * \Lambda_{L K}\right)>0$. This condition is satisfied if $\Theta>(<) 0$ and $\left(l * \lambda_{K 1}-\alpha h^{*} \Lambda_{L K}\right)>(<) 0$. Furthermore, the latter condition can be written as:

$$
\left(\theta_{K 1} / \theta_{L 1}\right)>(<)\left[\alpha h^{*} \theta_{K} /\left(l *+\alpha h^{*}\right) \theta_{L}\right]
$$


where $\theta_{K}=r K / Y, \theta_{L}=w_{1} L / Y$, and $Y$ is the national income.

The result is summarized as follows.

Proposition 2. Simultaneous immigration of skilled labor and emigration of unskilled labor will increase the wage inequality if:

$$
\frac{\theta_{K 2}}{\theta_{H 2}}>(<) \frac{\theta_{K 1}}{\theta_{L 1}}>(<) \frac{\alpha h^{*} \theta_{K}}{\left(l^{*}+\alpha h^{*}\right) \theta_{L}}
$$

where $\theta_{K}=r K / Y, \theta_{L}=w_{1} L / Y$, and $Y$ is the national income.

If Sector 2 is capital intensive $(\Theta>0)$, the immigration of skilled labor reduces the wage inequality while the emigration of unskilled labor increases the inequality. If the latter effect is larger than the former one, the simultaneous movements of skilled and unskilled labor worsens the wage inequality. The second inequality of the proposition provides the condition for the detrimental effect on the wage inequality. Wage inequality will expand if there is only a small beneficial effect from the inflow of skilled labor, which occurs if: (i) the inflow of skilled labor is small relative to the outflow of unskilled labor (small $\alpha$ ), (ii) the initial level of foreign skilled labor is low (small $h^{*}$ ), and (iii) the share of capital income is small relative to that of the unskilled labor income $\left(\theta_{K}<\theta_{L}\right)$. If Sector 1 is capital intensive, these results are reversed.

\section{B. Capital and skilled labor}

Another important example of international factor movement is the simultaneous movement of capital and skilled labor. This is commonly observed when Multinational Firms (MNFs) establish their subsidiaries in the host countries. Along with capital, MNFs send skilled labor such as managers, engineers, and marketing experts to the host countries. If we consider a simple but feasible case where the rate of skilled labor to capital is stable, we can assume that:

$$
\hat{H}^{*}=\hat{K}^{*}
$$


From Equations (10) and (16), therefore, the following is obtained:

$$
\left(\hat{s}-\hat{w}_{1}\right)=\left(w_{1} \lambda \Theta / \Delta\right)\left(h * \Lambda_{L K}-k^{*} \lambda_{L 1}\right) \hat{K}^{*}
$$

Therefore, the following proposition is immediate.

Proposition 3. Simultaneous increase in capital and skilled labor will decrease the wage inequality if:

$$
\frac{\theta_{K 2}}{\theta_{H 2}}>(<) \frac{\theta_{K 1}}{\theta_{L 1}}>(<) \frac{\left(h^{*}-k^{*}\right) \theta_{K}}{h^{*} \theta_{L}}
$$

If Sector 2 is capital intensive $(\Theta>0)$, the inflow of capital increases the wage inequality while the inflow of skilled labor decreases it. If the latter effect is larger than the former one, the wage inequality eventually decreases due to the simultaneous inflow of both capital and skilled labor. This result is more likely if $h^{*}$ is small relative to $k^{*}$ and/or $\theta_{k}$ is small relative to $\theta_{L}$. If Sector 1 is capital intensive, the results are reversed.

In the previous studies, it is known that the effect of the international factor movement of single factor on the wage inequality depends only on the factor intensity condition. However, the results show that two other aspects, that is, the initial amount of foreign factors and the shares of factors in national income must be considered in the case where multiple factors move simultaneously. Thus, for example, the result expected from the factor intensity condition $(\Theta>0)$ may be reversed if $h^{*}$ is large relative to $k^{*}$ and/or $\theta_{k}$ is large relative to $\theta_{L}$.

The results are summarized in the following table. 
Table 1. Summary of the results

\begin{tabular}{|l|c|l|l|}
\hline Factor movements & Examples & Results (The change in WI) & \multicolumn{1}{c|}{ Evaluation } \\
\hline $\begin{array}{l}\text { (A) Skilled and } \\
\text { unskilled labor } \\
\text { (same direction) }\end{array}$ & $\begin{array}{c}\text { EPA } \\
\text { (Japan-Philippine) }\end{array}$ & $\uparrow$ if $\Theta>0$ & $\begin{array}{l}\text { (A) The result is intuitive } \\
\text { and confirms the previous } \\
\text { ones. }\end{array}$ \\
\hline $\begin{array}{l}\text { (B) Skilled and } \\
\text { unskilled labor } \\
\text { (opposite direction) }\end{array}$ & $\begin{array}{l}\text { EU } \\
\text { (Germany-Italy) }\end{array}$ & $\begin{array}{l}\uparrow \text { if both } \Theta>(<) 0 \text { and } \\
\left(l * \lambda_{K 1}-\alpha h^{*} \Lambda_{L K}\right)>(<) 0 \\
\text { or Equation }(16) \text { in the text }\end{array}$ & $\begin{array}{l}\text { (B) }(\mathrm{C}) \text { The results are } \\
\text { newd specify the } \\
\text { conditions for the change } \\
\text { in WI. }\end{array}$ \\
\hline $\begin{array}{l}\text { (C) Capital and } \\
\text { skilled labor }\end{array}$ & TPP (US-Japan) & $\begin{array}{l}\uparrow \text { if both } \Theta>(<) 0 \text { and } \\
\left(l * \lambda_{K 1}-\alpha h * \Lambda_{L K}\right)>(<) 0 \\
\text { or Equation }(19) \text { in the text }\end{array}$ & \\
\hline
\end{tabular}

(Notes) (i) $\Theta=\left(\theta_{K 2} \theta_{L 1}-\theta_{K 1} \theta_{H 2}\right)$.

(ii) $\mathrm{EPA}=$ Economic Partnership Agreement, TPP=Trans-Pacific Partnership, WI=Wage Inequality.

\section{Concluding Remarks}

In this paper, the effects of the simultaneous movements of the factors in a two good and three factor general equilibrium model with unemployment have been examined. The analysis sheds more light on the complex effects of factor movements, following the establishment of Free Trade Agreements (FTAs) or Economic Partnership Agreements (EPAs), on the skilled-unskilled wage inequality.

In the case where skilled and unskilled workers move in the same direction, the effect on the wage inequality is reinforced on its own. In the other case, where skilled and unskilled workers move in the opposite direction, the immigration of skilled labor may eventually worsen the wage inequality due to the detrimental effect of migration of unskilled labor. Finally, in the case of simultaneous inflow of capital and skilled labor, the host countries tend to oppose the inflow of skilled labor and require the promotion of local employment. However, our result shows that the inflow of skilled labor along with 
capital contributes to lowering the wage inequality and eventually improves inequality under the given conditions regarding the capital intensity of the sector(s), the initial amount of foreign factors, and the shares of factors in national income. This paper has provided the precise conditions and interpreted them.

This paper focuses its attention on wage inequality. Our framework can also be used to effectively examine other aspects of the simultaneous international movement of such factors as unemployment, production, and welfare.

Received 29 August 2014, Revised 26 September 2014, Accepted 22 July 2015

\section{References}

Beladi, Hamid, Sarbajit Chaudhuri, and Shigemi Yabuuchi. "Can International Factor Mobility Reduce Wage Inequality in a Dual Economy." Review of International Economics 16 (2008): 893-903.

Banerjee, Rakhi, and Ranjanendra N. Nag. "Globalization, Labour Market Segmentation, Unemployment and Wage Inequality.” Journal of Economic Integration 26 (2011): 578599.

Davis, Donald. "Technology, Unemployment, and Relative Wages in a Global Economy," European Economic Review 42 (1998): 1613-1633.

Feenstra, Robert C., and Gordon H. Hanson. "Foreign Investment, Outsourcing and Relative Wages." In Political Economy of Trade Policies: Essays in Honor of J. $N$. Bhagwati, edited by Feenstra, Robert C., Gene M. Grossman, and Douglas A. Irwin, 89127. Cambridge: MIT Press, 1996.

Feenstra, Robert C., and Gordon H. Hanson. "Foreign Direct Investment and Relative Wages: Evidence from Mexico's Maquiladoras." Journal of International Economics 42 (1997): 371-393.

Harris, John R., and Michael Todaro. "Migration, Unemployment and Development: A Two-Sector Analysis.” American Economic Review 60 (1970): 126-142. 
Jones, Ronald W., and Sugata Marjit. "Economic Development, Trade and Wages," German Economic Review 4 (2003): 1-17.

Lee, Cheng-Te, Chung-Jen Wu, and Yi-Chen Lee. "Globalization, Wage Inequality and Unemployment." Journal of Economics and Management 6 (2010): 1-15.

Marjit, Sugata, and Rajat Acharyya. International Trade, Wage Inequality and the Developing Economy: A General Equilibrium Approach. New York: Physica-Verlag, 2003.

Marjit, Sugata, and Saibal Kar. "Emigration and Wage Inequality." Economics Letters 88 (2005): 141-145.

Yabuuchi, Shigemi. "Emigration and Wage Inequality in a Dual Economy." Economics Bulletin 29 (2009): 1549-1554. 


\section{Appendix: Comparative Statics}

Differentiating Equations (1) to (6) and given that $w_{2}, L, H$, and $K$ are constant, the following is obtained:

$$
\left[\begin{array}{cccccc}
0 & \theta_{H 2} & \theta_{K 2} & 0 & 0 & 0 \\
\theta_{L 1} & 0 & \theta_{K 1} & 0 & 0 & 0 \\
\lambda_{L 1} S_{L L}^{1} & 0 & A & (1+\lambda) \lambda_{L 2} & \lambda_{L 1} & \lambda \lambda_{L 2} \\
0 & 0 & 0 & 1 & 0 & 0 \\
\lambda_{K 1} S_{K L}^{1} & 0 & B & \lambda_{K 2} & \lambda_{K 1} & 0 \\
(1+\lambda) w_{1} & 0 & 0 & 0 & 0 & \lambda w_{1}
\end{array}\right]\left[\begin{array}{c}
\hat{w}_{1} \\
\hat{s} \\
\hat{r} \\
\hat{X}_{2} \\
\hat{X}_{1} \\
\hat{\lambda}
\end{array}\right]=\left[\begin{array}{c}
\hat{p}_{2} \\
\hat{p}_{1} \\
l^{*} \hat{L}^{*} \\
h^{*} \hat{H}^{*} \\
k^{*} \hat{K}^{*} \\
0
\end{array}\right]
$$

where $l^{*}=L^{*} /\left(L+L^{*}\right), h^{*}=H^{*} /\left(H+H^{*}\right), k^{*}=K^{*} /\left(K+K^{*}\right), A=(1+\lambda) \lambda_{L 2} S_{L K}^{2}+$ $\lambda_{L 1} S_{L K}^{1}>, B=\lambda_{K 2} S_{K K}^{2}+\lambda_{K 1} S_{K K}^{1}<0, S_{L K}^{2}=\left(r / a_{L 2}\right)\left(\partial a_{L 2} / \partial r\right)$, and so on.

Solving Equations (18) for $\hat{w}_{1}$ and $\hat{S}$ with respect to $\hat{L}^{*}, \hat{H}^{*}$, and $\hat{K}^{*}$, this study finds Equations (8) and (9) in the main text. Other results on comparative statics are similarly obtained. 